\title{
Corrigendum: Intrinsic symmetry of Ampère's circuital law and other educational issues
}

Joaquim Anacleto, José Manuel M.M. de Almeida, and J.M. Ferreira

\section{Ref.: Can. J. Phys. 90, 67 (2012).}

In a recent paper [1], Anacleto et al. illustrated the concept of displacement current from an educational perspective using a conducting wire segment connecting two opposite charges. We have just become aware that this same problem had previously been addressed by Charitat and Graner [2]. We regret that we were unaware of ref. 2 at the time of writing our paper and fully acknowledge Charitat and Graner's [2] priority in originally analyzing the aforementioned illustrative example.

\section{References}

1. J. Anacleto, J.M.M.M. de Almeida, and J.M. Ferreira. Can. J. Phys. 90, 67 (2012). doi:10.1139/p11-141.

2. T. Charitat and F. Graner. Eur. J. Phys. 24, 267 (2003). doi:10.1088/0143-0807/24/3/306. 